\title{
Combined treatment of the experimental human papilloma virus-16-positive cervical and head and neck cancers with cisplatin and radioimmunotherapy targeting viral
} E6 oncoprotein

\begin{abstract}
M Harris ${ }^{1}$, X G Wang ${ }^{1,2}$, Z Jiang ${ }^{1}$, R Phaeton ${ }^{3}$, W Koba ${ }^{1}$, G L Goldberg ${ }^{3}$, A Casadevall ${ }^{4,5}$ and E Dadachova*,1,4 ${ }^{1}$ Department of Radiology, Albert Einstein College of Medicine, 1695A Eastchester Road, Bronx, NY 10461, USA; ${ }^{2}$ The Faculty of Life sciences, Hubei University, Wuhan, China; ${ }^{3}$ Department of Obstetrics and Gynecology and Women's Health, Division of Gynecologic Oncology, Bronx, NY, USA; ${ }^{4}$ Department of Microbiology and Immunology, Albert Einstein College of Medicine, Bronx, NY, USA and ${ }^{5}$ Department of Medicine, Albert Einstein College of Medicine, Bronx, NY, USA
\end{abstract}

Background: Human papilloma virus (HPV) is implicated in $>99 \%$ of cervical cancers and $\sim 40 \%$ of head and neck squamous cell carcinoma (HNSCC). We previously targeted E6 oncogene with ${ }^{188}$ Rhenium-labelled monoclonal antibody (mAb) C1P5 to HPV16 E6 in cervical cancer and HNSCC. Intranuclear E6 can be accessed by mAbs in non-viable cells with leaky membranes. As radioimmunotherapy (RIT) efficacy depends on the availability of target protein - we hypothesised that pretreatment with cisplatin will kill some tumour cells and increase E6 availability for RIT.

Methods: Mice with subcutaneous HPV16 + cervical (CasKi) and HNSCC (2A3) tumours were pretreated with 0-7.5 $\mathrm{mg} \mathrm{kg}^{-1} \mathrm{per}$ day cisplatin for 3 days followed by ${ }^{188} \mathrm{Re}-\mathrm{C} 1 \mathrm{P} 5$ and biodistribution was performed $24 \mathrm{~h}$ later. For RIT, the animals were treated with: $5 \mathrm{mg} \mathrm{kg}^{-1}$ per day cisplatin for 3 days; or $5 \mathrm{mg} \mathrm{kg}^{-1}$ per day cisplatin for 3 days followed 200 or $400 \mu \mathrm{Ci}{ }^{188} \mathrm{Re}-\mathrm{C} 1 \mathrm{P} 5 \mathrm{mAb}$; or 200 or $400 \mu \mathrm{Ci}{ }^{188} \mathrm{Re}-\mathrm{C} 1 \mathrm{P} 5 \mathrm{mAb}$; or left untreated, and observed for tumour growth for 24 days.

Results: Pretreatment with cisplatin increased the uptake of ${ }^{188} \mathrm{Re}-\mathrm{C} 1 \mathrm{P} 5$ in the tumours 2.5 to 3.5 -fold and caused significant retardation in tumour growth for CasKi and 2A3 tumours in both RIT alone and cisplatin, and RIT groups in comparison with the untreated control and cisplatin alone groups $(P<0.05)$. The combined treatment was more effective than either modality alone $(P<0.05)$.

Conclusion: Our study demonstrates that preceding RIT targeting E6 oncogene with chemotherapy is effective in suppressing tumour growth in mouse models of HPV16 + cancers.

The human papilloma virus (HPV) is implicated in roughly $95 \%$ of all cervical cancers and $\sim 40 \%$ of all head and neck cancers worldwide. This correlates with $>500000$ cases of cervical cancer annually that kills around 200000 women a year (WHO data). Head and neck squamous cell carcinoma (HNSCC) is the sixth most common cancer among men and women, with about 640000 new cases each year worldwide (WHO data). The presence of HPV is also a risk factor for the development of penile, vulvar and anal cancers. The oncogenes E6 and E7 of the high-risk HPV types (16 and 18) are able to immortalise epithelial cells in tissue culture and 
can increase cellular transformation with other oncoproteins, inhibiting the tumour suppressor genes p53 and retinoblastoma. The E6 oncoprotein binds p53, causing its rapid degradation via the ubiquitin-dependent pathway. Conversely, the E7 oncoprotein binds the retinoblastoma protein diminishing cell cycle regulation (Percoraro et al, 1989; Kaur et al, 1989a,b; Hoffman et al, 2004). The ability of these oncoproteins to cause malignant transformation in normal cells makes them logical targets for the development of novel therapies for HPV-related cancers.

Radioimmunotherapy (RIT) uses tumour antigen-specific monoclonal antibodies (mAbs) for targeted delivery of cytocidal ionising radiation to tumour cells (Sharkey and Goldenberg, 2006). Currently, RIT is approved for the treatment of primary, recurrent and refractory non-Hodgkin lymphoma. Several years ago we suggested targeting viral antigens on the tumours with RIT (Dadachova et al, 2007). This approach is fundamentally different from traditional applications of RIT that have been focused on 'self human antigens, as viral proteins bear little homology to the human proteins, which should translate into high selectivity of tumour targeting and as a result-into low toxicity of treatment. In previous studies we have shown that it is feasible and effective to target the intranuclear E6 oncoprotein in experimental cervical, as well as HNSCC cancers by radiolabelling E6-specific mAb with the beta-emitter 188-Rhenium ( ${ }^{188} \mathrm{Re}$ ) (Wang et al, 2007; Phaeton et al, 2010a,b; Harris et al, 2011). The RIT approach is made possible by the fact that most aggressive tumours contain large numbers of dead and dying cells with compromised cellular membranes that permit antibody to access intracellular viral antigens. Given that the mechanism of targeting intranuclear E6 with the antibody involves binding to the extracellular E6 released from dying cells, we hypothesised that the administration of a chemotherapeutic agent followed by RIT would facilitate the delivery of cytocidal radiation to the tumours due to the increased presence of free E6. Here, we present the results of the investigation demonstrating that pretreating experimental $\mathrm{HPV}+$ cervical and head and neck cancers with the conventional chemotherapy drug cisplatin before RIT targeting E6 oncoprotein lead to more effective treatment than either modality alone.

\section{MATERIALS AND METHODS}

Cell lines, antibodies and reagents. The HPV16 + CasKi cell line was obtained from the American Type Culture Collection (Manassas, VA, USA). The HPV16 + 2A3 cell line was produced by stably transfecting the FaDu cell line from the American Type Culture Collection with the LXSN 16E6/E7 as described in Harris et al (2011). Murine anti-HPV16-E6 C1P5 and anti-HPV16-E7 20191 mAbs (both of IgG1 isotype) were obtained from Abcam (Boston, MA, USA) and irrelevant isotype matching control murine mAb MOPC21 was procured from Abnova (Taipei, Taiwan). BD Matrigel Basement Membrane Matrix was purchased from BD Biosciences (Rockville, MD, USA), the lactate dehydrogenase (LDH) assay kit-from Roche Applied Science (Indianapolis, IN, USA). Cis-diamminedichloroplatinum (II) (cisplatin) was procured from Sigma-Aldrich (St Louis, MO, USA). The betaemitter ${ }^{188} \mathrm{Re}$ with a half-life of $16.9 \mathrm{~h}$ was produced from beta decay of 188 -Tungsten $\left({ }^{188} \mathrm{~W}\right)$ parent (half-life 69 days) using a ${ }^{188} \mathrm{~W} /{ }^{188} \mathrm{Re}$ generator (Oak Ridge National Laboratory, Oak Ridge, TN, USA). ${ }^{188} \mathrm{Re}$ was eluted from the generator in the form of sodium perrhenate, and the C1P5 mAb was labelled 'directly' with ${ }^{188} \mathrm{Re}$ through binding of reduced ${ }^{188} \mathrm{Re}$ to the generated $-\mathrm{SH}$ groups on the mAb as previously described (Wang et al, 2007).

Assessment of cisplatin effect on CasKi and $2 \mathrm{~A} 3$ cells. CasKi and $2 \mathrm{~A} 3$ cells (5000 cells per well) were added to a 96-well plate in complete media for $1 \mathrm{~h}$ at $37^{\circ} \mathrm{C}$. The cells were then washed with
PBS and various concentrations of cisplatin were added $(0-40 \mu \mathrm{M})$ for $12 \mathrm{~h}$ at $37^{\circ} \mathrm{C}$. The supernatants were then removed, transferred to a new 96-well plate and the percentage of cells with leaky membranes was quantified using $\mathrm{LDH}$ assay kit as per manufacturer's instructions.

Cervical and HNSCC tumour models. All animal studies were carried out in accordance with the guidelines of the Institute for Animal Studies at the Albert Einstein College of Medicine. Six to eight-weeks-old athymic $\mathrm{Nu} / \mathrm{Nu}$ balb/c nude mice were purchased from Charles River Laboratories (Wilmington, MA, USA). Ten million Caski or $2 \mathrm{~A} 3$ cells were mixed with $80 \%$ Matrigel and injected subcutaneously into the right flank of each mouse. The tumour size was measured every 3 days with electronic calipers (Pro-max Sylvac System IP67, Fowler Tools and Instruments, Boston, MA, USA) in three dimensions and the tumour volume was calculated as a product of three dimensions divided by 2 .

Effect of cisplatin on the uptake of ${ }^{188}$ Re-labelled C1P5 mAb in cervical and HNSCC tumours. To investigate whether the pretreatment of cervical and HNSCC tumours with cisplatin results in increased tumour uptake of ${ }^{188}$ Re-labelled C1P5 mAb, mice with either CasKi or $2 \mathrm{~A} 3$ tumours measuring $0.5-0.7 \mathrm{~cm}$ in diameter were randomized into eight groups of five mice and injected intraperitoneally (IP) for 3 days with either $0,2,3$, $5 \mathrm{mg} \mathrm{kg}^{-1}$ per day cisplatin (CasKi) or $0,2.5,5,7.5 \mathrm{mg} \mathrm{kg}^{-1}$ per day cisplatin (2A3). On the 4 th day, all groups were injected IP with $100 \mu \mathrm{Ci}{ }^{188} \mathrm{Re}-\mathrm{C} 1 \mathrm{P} 5$ and $24 \mathrm{~h}$ later the tumours were harvested and divided into two parts. One part of each tumour was dry weighted, counted in a gamma counter (Wallac, Turku, Finland) and the percentage of injected dose per gram tumour (ID $\left.\mathrm{g}^{-1}, \%\right)$ was calculated. The other part of each tumour was fixed in buffered formalin and subsequently subjected to the histological evaluation for the presence of the apoptosis by TUNEL assay, which was performed according to the manufacturer's instructions (in Situ Cell Death Detection Kit, Fluorescein, Roche Applied Science).

Therapy of cervical and HNSCC tumours in mice with ${ }^{188}$ Re-labelled C1P5 mAb with or without cisplatin pretreatment. For therapeutic studies mice with cervical or HNSCC tumours measuring $0.5-0.7 \mathrm{~cm}$ in diameter were randomized into eight groups of five mice. The mice with CasKi cervical tumours were treated IP with: $200 \mu \mathrm{Ci}{ }^{188} \mathrm{Re}-\mathrm{C} 1 \mathrm{P} 5 \mathrm{mAb}$ on day 0 ; or $5 \mathrm{mg} \mathrm{kg}^{-1}$ per day cisplatin on days $0,1,2$ followed by $200 \mu \mathrm{Ci}$ ${ }^{188} \mathrm{Re}-\mathrm{C} 1 \mathrm{P} 5 \mathrm{mAb}$ on day 3 ; or $5 \mathrm{mg} \mathrm{kg}^{-1}$ cisplatin alone on days 0 . 1, 2; or left untreated. The mice with $2 \mathrm{~A} 3 \mathrm{HNSCC}$ tumours were treated IP with: $400 \mu \mathrm{Ci}{ }^{188} \mathrm{Re}-\mathrm{C} 1 \mathrm{P} 5 \mathrm{mAb}$ on day 0 ; or $5 \mathrm{mg} \mathrm{kg}^{-1}$ per day cisplatin on days $0,1,2$ followed by $400 \mu \mathrm{Ci}{ }^{188} \mathrm{Re}-\mathrm{C} 1 \mathrm{P} 5$ $\mathrm{mAb}$ on day 3; or $5 \mathrm{mg} \mathrm{kg}^{-1}$ cisplatin alone on days 0,1 , 2; or left untreated. They were observed for tumour growth and survival for 24 days with the tumour size measured every 3 days as described above. The experiment was performed twice.

Micro Positron Emission Tomography/Computer Tomography of RIT or chemotherapy treated mice with cervical and 2A3 tumours. Positron emission tomography (PET) utilises the accumulation of ${ }^{18} \mathrm{~F}$-labelled fluorodeoxyglucose $\left({ }^{18} \mathrm{~F}-\mathrm{FDG}\right)$ in the tumours to image cancer patients before and after initiation of treatment while computer tomography (CT) component assists with the anatomical localisation of the tumours. To compare the effects of RIT in combination with cisplatin or cisplatin alone on the tumours in our study the way it would be done in the clinicwe performed micro positron emission tomography (microPET)/ CT of untreated mice, treated with cisplatin alone or with the cisplatin and RIT on day 15 post treatment. Before administration of ${ }^{18} \mathrm{~F}$-FDG the mice were fasted for $3 \mathrm{~h}$, and then placed in an anaesthesia chamber with $1.5 \%$ isoflurane-oxygen mixture. Anaesthesia was continued until the completion of the imaging 
portion of the procedure. Each mouse was placed near a heating pad before scanning to maintain normal body temperature. Mice were injected via tail-vein with $11.1-14.8 \mathrm{MBq}$ (300 to $400 \mu \mathrm{Ci}$ ) ${ }^{18} \mathrm{~F}-\mathrm{FDG}$ and $1 \mathrm{~h}$ later imaged in an Inveon Multimodality Scanner (Siemens, Malvern, PA, USA) using its PET/CT module. Positron emission tomography imaging was performed using the PET gantry, which provides $12.7 \mathrm{~cm}$ and $10 \mathrm{~cm}$ transaxial active field of view with a resolution of $<1.5 \mathrm{~mm}$. After each acquisition, the images are reconstructed using 2D-Ordered Subset Expectation Maximisation algorithm. The data were corrected for dead time counting losses, random coincidences and the measured nonuniformity of detector response. Image and data analysis was performed using ASIPRO (Siemens) dedicated software.

Effect of RIT on the levels of E6 and E7 oncogenes expression in CasKi and 2A3 tumour cells. CasKi and 2A3 cells were grown as described above, washed with sterile PBS, placed into Eppendorf tubes in the amount of $10^{5}$ cells per tube in $1 \mathrm{ml}$ PBS and incubated for $3 \mathrm{~h}$ at $37^{\circ} \mathrm{C}$ with $20 \mu \mathrm{Ci}{ }^{188} \mathrm{Re}-\mathrm{C} 1 \mathrm{P} 5 \mathrm{mAb}$ or left untreated. After the incubation, the unbound $\mathrm{mAb}$ was removed by the centrifugation, the cells were transferred into the 24-well plates and grown in their respective media for 3 days. The cells were subsequently collected, fixed and analysed for the expression of E6 and E7 using Histostain-Plus Kit (DAB, Broad Spectrum) (Life Technologies, Grand Island, NY, USA) according to the manufacturer's instructions. C1P5 and $20191 \mathrm{mAbs}$ to E6 and E7,

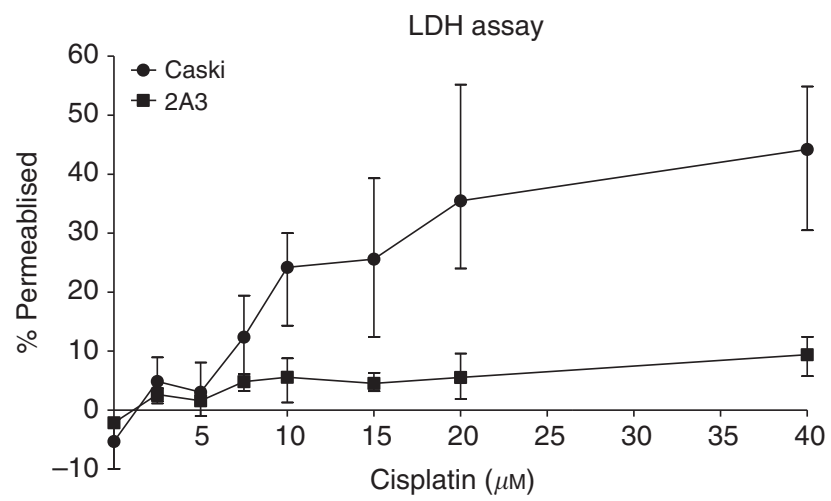

Figure 1. Lactate dehydrogenase assay of CasKi and 2A3 cells treated in vitro with various concentrations of cisplatin. respectively, were used as primary antibodies, and the negative controls were incubated with control MOPC21 mAb instead of primary antibody under the same conditions.

Statistical analysis. The differences between the tumour sizes for differently treated groups in the biodistribution and RIT studies were analysed by non-parametric two-tailed Mann-Whitney test using Prism software (GraphPad, San Diego, CA, USA). The differences were considered statistically significant when $P$-values were $<0.05$.

\section{RESULTS}

Susceptibility of CasKi and $2 \mathrm{~A} 3$ cells to cisplatin. We analysed the effect of various concentrations of cisplatin on CasKi and 2A3 cells using an LDH assay. We found CasKi cells being much more susceptible to cisplatin damage in vitro with $10-20 \mu \mathrm{M}$ concentrations of the latter resulting in $\sim 30 \%$ of CasKi cells loosing the integrity of cellular membranes, while in the case of $2 \mathrm{~A} 3$ cells $40 \mu \mathrm{M}$ cisplatin caused $\sim 5 \%$ cells to become leaky (Figure 1 ).

Pretreatment with cisplatin increased the uptake of ${ }^{188} \mathrm{Re}-\mathrm{C} 1 \mathrm{P} 5$ $\mathrm{mAb}$ in cervical and HNSCC tumours in mice. Pretreating the mice bearing either cervical CasKi or HNSCC $2 \mathrm{~A} 3$ tumours for 3 days with the range of cisplatin doses resulted in 2.5 to 3.5 -fold increase in the ${ }^{188} \mathrm{Re}-\mathrm{C} 1 \mathrm{P} 5 \mathrm{mAb}$ tumour uptake in comparison with the non-treated tumours (Figure $2 \mathrm{~A}$ and $\mathrm{B}$ ), which was statistically significant for all concentrations in both CasKi and $2 \mathrm{~A} 3$ tumours $(P<0.05)$. The difference in the ${ }^{188} \mathrm{Re}-\mathrm{C} 1 \mathrm{P} 5 \mathrm{mAb}$ tumour uptake between the various concentrations of cisplatin was not statistically significant in both CasKi and 2A3 groups. Histological evaluation of the TUNEL stained slides of the tumours showed that pretreatment with cisplatin resulted in the increase in the number of apoptotic cells in the treated tumours in comparison with untreated controls (Figure 2C and D). Based on these observations, the regimen of $5 \mathrm{mg} \mathrm{kg}^{-1}$ per day cisplatin for 3 days was selected as chemotherapy pretreatment for both CasKi and 2A3 tumour-bearing mice in RIT experiments.

Pretreatment with cisplatin followed by RIT was more effective than either RIT or cisplatin alone in treating both cervical and HNSCC tumours in nude mice. The therapy results expressed as normalised tumour volumes are shown in Figure 3A and B. All
A

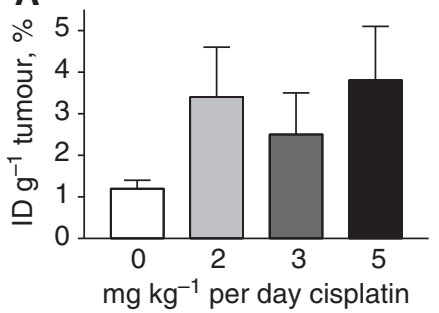

C
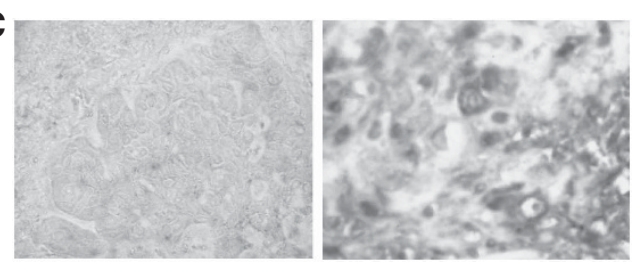

B

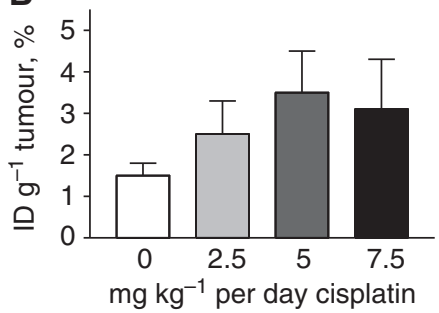

D

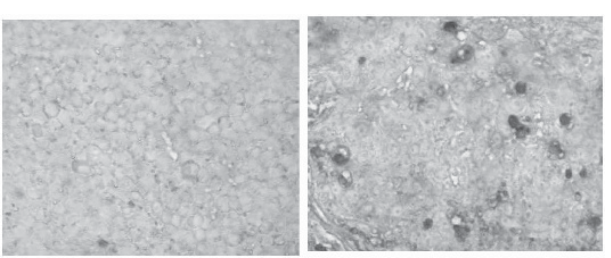

Figure 2. Tumour uptake of E6-binding mAb ${ }^{188} \mathrm{Re}-\mathrm{C} 1 \mathrm{P} 5$ in nude mice-bearing CasKi and $2 \mathrm{~A} 3$ tumours post treatment with cisplatin. Mice were treated with various doses of cisplatin for 3 days, ${ }^{188} \mathrm{Re}-\mathrm{C} 1 \mathrm{P} 5 \mathrm{mAb}$ was administered $24 \mathrm{~h}$ after the last dose of cisplatin, and the tumour uptake was assessed $24 \mathrm{~h}$ post ${ }^{188} \mathrm{Re}-\mathrm{C} 1 \mathrm{P} 5$ administration: (A) CasKi; (B) 2A3; (C, D) TUNEL staining of the untreated and cisplatin-treated tumours. Apoptotic cells stained brown. Original magnification $\times 400$ : (C) CasKi tumours—untreated (left panel) and treated with $5 \mathrm{mg} \mathrm{kg}^{-1} \mathrm{cisplatin}_{\text {(right }}$ panel); (D) 2A3 tumours-untreated (left panel) and treated with $5 \mathrm{mg} \mathrm{kg}^{-1}$ cisplatin (right panel). 

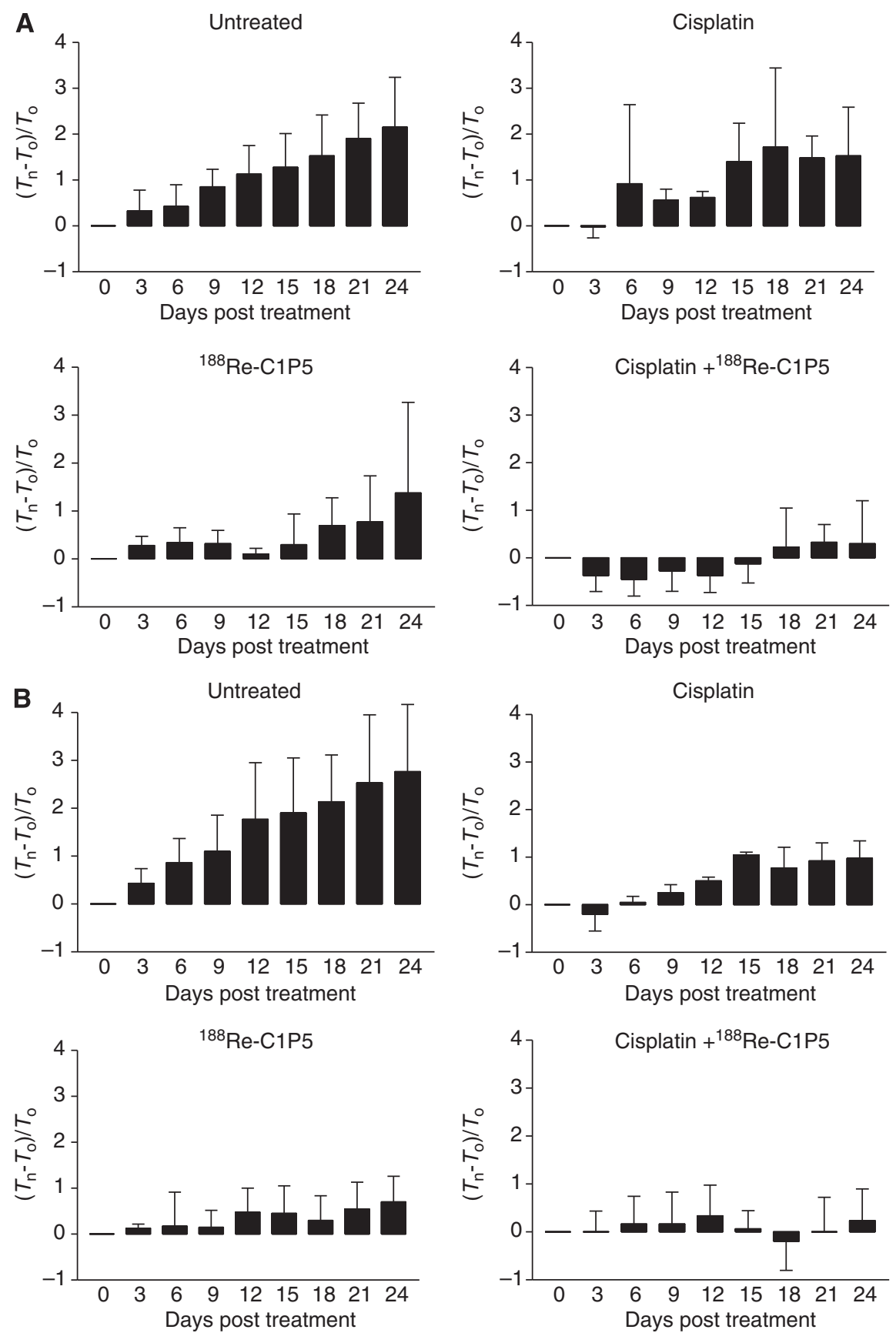

Figure 3. Therapy with cisplatin and RIT with E6-binding mAb ${ }^{188} \mathrm{Re}-\mathrm{C} 1 \mathrm{P} 5$ of nude mice-bearing $2 \mathrm{~A} 3$ (A) and CasKi (B) tumours. Tn-tumour volume on the day of measurement; $T_{0}$-tumour volume on day 0 . The mice with $2 \mathrm{~A} 3 \mathrm{HNSCC}$ tumours were treated IP with: $400 \mu \mathrm{Ci}{ }^{188} \mathrm{Re}-\mathrm{C} 1 \mathrm{P} 5$ $\mathrm{mAb}$ on day 0 ; or $5 \mathrm{mg} \mathrm{kg}^{-1}$ per day cisplatin on days $0,1,2$ followed by $400 \mu \mathrm{Ci}^{188} \mathrm{Re}-\mathrm{C} 1 \mathrm{P} 5 \mathrm{mAb}$ on day 3 ; or $5 \mathrm{mg} \mathrm{kg}^{-1}$ cisplatin alone on days 0, 1, 2; or left untreated. The mice with CasKi cervical tumours were treated IP with: $200 \mu \mathrm{Ci}{ }^{188} \mathrm{Re}-\mathrm{C} 1 \mathrm{P} 5 \mathrm{mAb}$ on day 0 ; or $5 \mathrm{mg} \mathrm{kg}{ }^{-1}$ per day cisplatin on days $0,1,2$ followed by $200 \mu \mathrm{Ci}^{188} \mathrm{Re}-\mathrm{C} 1 \mathrm{P} 5 \mathrm{mAb}$ on day 3 ; or $5 \mathrm{mg} \mathrm{kg}^{-1}$ cisplatin alone on days $0.1,2 ;$ or left untreated.

mice survived for the 24 days of observation, however, both untreated cervical CasKi and HNSCC 2A3 tumours grew aggressively with all mice in these two groups had to be killed on day 24 because of the large tumour volume. Cisplatin alone was able to retard the growth of $2 \mathrm{~A} 3$ tumours only during the 3 days of its administration followed by the almost unaltered tumour growth when compared with untreated control $(P=0.08)$. In mice with CasKi tumours treated with cisplatin, the growth retardation was observed up to day 6 followed by the significantly slowing tumour growth in comparison with untreated controls $(P=0.02)$. When ${ }^{188} \mathrm{Re}-\mathrm{C} 1 \mathrm{P} 5 \mathrm{mAb}$ alone was used for treatment of tumours, it caused significant slowing down of tumour growth for both CasKi and 2A3 tumours when compared with untreated controls ( $P=0.02$ and 0.04 , respectively) with one or two mice in each group whose tumours shrunk post treatment and did not grow throughout the observation period. The groups in which pretreatment with cisplatin preceded RIT administration demonstrated most impressive therapy results for both CasKi and 2A3 tumours. In mice with CasKi tumours, the growth in combined treatment group was significantly slower in comparison with both untreated controls $(P=0.001)$ and cisplatin alone group $(P=0.02)$, and the tumours in two mice in this group shrunk and did not regrow throughout the study. Though the statistical significance between the outcomes of RIT alone and cisplatin plus RIT for CasKi 

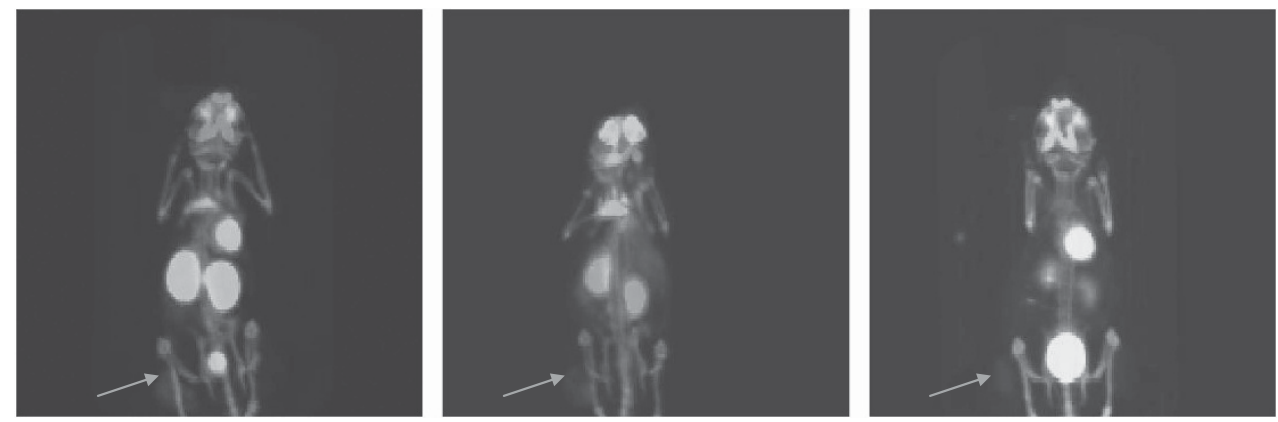

Figure 4. ${ }^{18} \mathrm{~F}$-FDG microPET/CT images of $2 \mathrm{~A} 3$ tumour-bearing on day 15 post treatment: left panel—untreated mouse, middle panel—the mouse treated with cisplatin alone, right panel-the mouse treated with cisplatin and RIT. Green arrows are pointing to the tumours.

tumours was not reached-there was a trend towards it with $P=0.06$. For mice with HNSCC $2 \mathrm{~A} 3$ tumours, the combined treatment group was significantly more effective in comparison with all three other treatment groups-untreated controls $(P=0.002)$, cisplatin alone $(P=0.006)$ and RIT alone $(P=0.03)$.

The microPET/CT imaging of the mice from different treatment groups confirmed the observations derived from the measurements of the tumours. Figure 4 shows the microPET/CT images of untreated mice with HNSCC 2A3 tumours (left panel), treated with cisplatin alone (middle panel) or with combined treatment (right panel). While the SUV of 8 (standardized uptake value) of ${ }^{18}$ F-FDG in the untreated tumours or SUV of 5 in cisplatin alone treated tumours seen attesting to the high metabolic activity in these tumours; the SUV of 1.5 in the combined treatment group is much less pronounced indicating that most of the cells in the tumour were dead or dormant at the time of imaging.

To gain the mechanistic insights into the RIT of CasKi and 2A3 tumours cells, we performed the additional experiments by treating the cells with RIT and then assessing the expression of E6 and E7 oncoproteins by immunohistochemistry. The experiments demonstrated that RIT resulted in decreased expression of E6 and E7 oncogenes in the treated samples for both CasKi and 2A3 tumour cells (Figure 5).

\section{DISCUSSION}

The poor prognosis for patients with metastatic cervical cancers, as well as for those with locally and systemically advanced HNSCC calls for novel approaches to treatment of these malignancies (Trimble and Frazer, 2009). The advantages of RIT when compared with the chemotherapeutic agents are the fact that antibody-antigen interaction is not a subject to the multidrug resistance mechanisms, its lack of systemic toxicity and relative independence of the patient's immune status. Radioimmunotherapy targeting various human antigens have been investigated for cervical cancer, as well as for HNSCC. More than two decades ago Chen et al (1989) targeted intranuclear DNA with TNT (tumour necrosis therapy) $\mathrm{mAb}$ radiolabelled with ${ }^{131} \mathrm{I}$ in mice-bearing cervical xenografts (Chen et al, 1989) Clinical experience in using RIT for HNSCC was reported in 13 patients with advanced HNSCC, treated with ${ }^{186}$ Re-labelled mAb U36 to the CD44v6 antigen overexpressed on the surface of cancer cells. The treatment with $13-80 \mathrm{mCi}{ }^{186} \mathrm{Re}-\mathrm{U} 36 \mathrm{mAb}$ was well tolerated and two patients had a reduction in tumour mass, and one was stable for 6 months while the rest experienced progressive disease (Colnot et al, 2001). This study set a precedent for using RIT in patients with HNSCC. In recent years, the attention turned to targeting epithelial growth factor receptor (EGFR) in experimental head and neck cancers using ${ }^{90} \mathrm{Y}$-labelled $\mathrm{mAbs}$ developed for EGFR inhibition in the clinic-cetuximab and panitumumab (Liu et al, 2010; Niu et al, 2010). Although significant tumour retardation was observed in tumour-bearing mice treated with the higher doses of these radiolabelled $\mathrm{mAbs}$, the limitation of these studies is that $\mathrm{mAbs}$ to human EGFR may not target murine EGFRs expressed in normal organs of mice resulting in fast systemic clearance of these mAbs and thus such treatment could not be a predictor of toxicity in patients.

In this study, we targeted E6 HPV16 viral oncoprotein, which is expressed only in the tumours in both mouse models and in patients. A rationale for combining chemotherapy with cisplatin, which is approved for treatment of patients with metastatic cervical cancer and HNSCC (Kies et al, 2010; Sehouli et al, 2012) and RIT was the premise that cisplatin would kill some tumour cells and liberate intranuclear E6 to provide more target for RIT. Cisplatin has been used previously in mouse models of cervical and head and neck cancers, and treatments with the clinically relevant 20 and $37.5 \mathrm{mg} \mathrm{kg}^{-1}$, respectively (Banuelos et al, 2009; Duarte et al, 2010), were effective in slowing tumour growth with relatively little toxicity. In this study, we utilised much lower doses of cisplatin to avoid possible masking of RIT effects and the toxicity of the combination treatment. Histological analysis of CasKi and 2A3 tumours taken from mice pretreated with cisplatin demonstrated an increased amount of apoptotic cells by TUNEL assay. This is consistent with cisplatin's mechanism of action, which causes the formation of irreversible intra- and interstrand crosslinks with bases in DNA, ultimately triggering apoptosis (Rosenberg, 1985). The biodistribution of ${ }^{188} \mathrm{Re}-\mathrm{C} 1 \mathrm{P} 5 \mathrm{mAb}$ to $\mathrm{E} 6$ in cisplatin pretreated mice showed the statistically significant increased uptake in the tumours in comparison with untreated controls confirming the notion that cell death liberated some intranuclear E6. The increase in uptake of the ${ }^{188} \mathrm{Re}-\mathrm{C} 1 \mathrm{P} 5$ was not statistically different for increasing doses of cisplatin pretreatment, which can be explained by the fact that the uptake of the radiolabelled mAbs into the tumours is limited by the tumour vascularisation and once the tumour cells in the vicinity of the existing blood vessel are killed-the mAb uptake cannot increase any more in response to chemotherapy.

The most obvious result of the therapy study was clear superiority of RIT over chemotherapy in the ability to control the tumour growth after day 15, as well as the superiority of combination therapy relative to monotherapy. In RIT-treated samples very few cells expressing E6 or E7 oncogenes were left behind, attesting to the specificity of treatment. In patients with many different cancers including cervical cancer and HNSCC the early response to therapy correlates with the significant decrease in ${ }^{18}$ F-FDG tumour uptake during PET due to an inability of dying or dead cells to actively take-up glucose and predicts the overall response to therapy (Huang and Ravi Kumar, 2012; Schwartz et al, 2012). Likewise, in tumour-bearing mice treated with chemotherapy, the decrease in ${ }^{18} \mathrm{~F}$-FDG tumour uptake in comparison with the baseline value was much less pronounced than in mice treated 

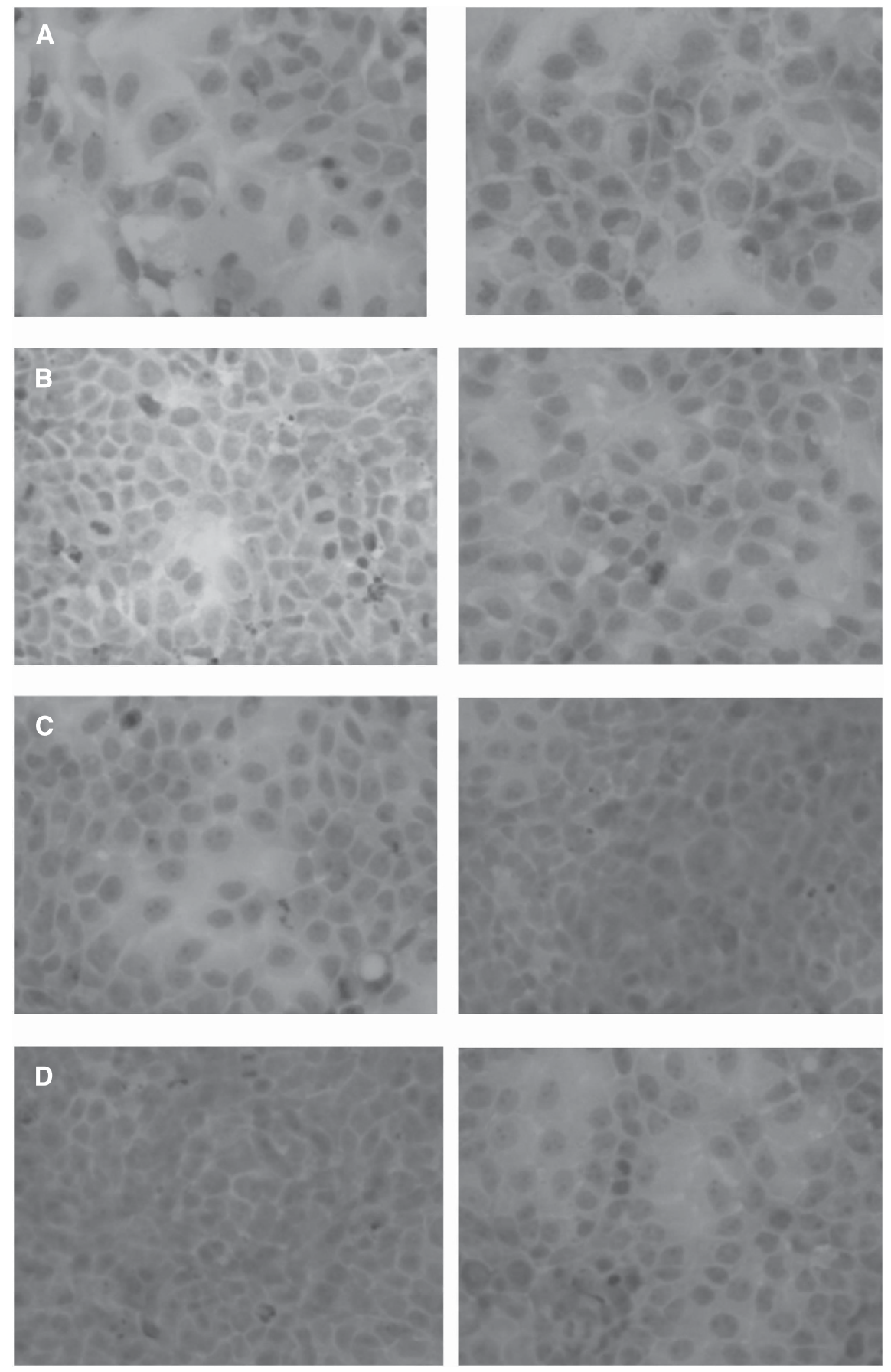

Figure 5. Immunohistochemical evaluation of E6 and E7 oncogenes expression in RIT-treated CasKi and 2A3 cells. (A) E6 in CasKi cells, (B) E7 in CasKi cells; (C) E6 in 2A3 cells; (D) E7 in 2A3 cells. Left panels show untreated cells and right panels RIT-treated cells. Cells positive for E6 and E7 oncogenes stained brown. Original magnification $\times 400$.

with combination therapy. Importantly, the combination therapy was significantly more effective than either RIT or chemotherapy alone in mice with $2 \mathrm{~A} 3 \mathrm{HNSCC}$ tumours and there was a trend for the combination therapy being more effective than RIT alone in mice with CasKi cervical tumours. In this regard, our group has observed the same synergistic effect between chemotherapy (dacarbazine) and RIT with melanin-binding antibody in experimental mouse melanoma (Revskaya et al, 2009). There was no weight loss or change in eating/behaviour of the RIT-treated mice attesting to the very-low toxicity of RIT. In this regard, the maximum tolerated dose for IgGs labelled with ${ }^{188} \mathrm{Re}$ in mice is around $800 \mu \mathrm{Ci}$ (Sharkey et al, 1997) and the doses administered in our study were several times lower.

In conclusion, we have demonstrated that combination of cisplatin and RIT targeting E6 viral oncoprotein on HPV16+ experimental cervical and head and neck cancers is more effective than either modality alone. These results are important for the development of novel RIT-based treatments for patients with advanced cervical cancer as the majority of such patients are treated with chemotherapy during the course of the disease and thus would benefit from the addition of RIT to their therapeutic regimens. In regard to the metastatic head and neck cancers it 
should be noted that metastatic HPV16 + head and neck cancers are relatively rare. The clinical outcomes for patients with HPV16 + HNSCC are different from those with HPV16-negative tumours (Ang et al, 2010) due to the low-malignant character of a HPV-positive HNSCC, which will probably limit the potential applications of systemic chemo and RIT combination to only some patients with metastatic HPV16+. However, it remains to be investigated if intratumoural RIT could replace external beam radiation therapy (EBRT) for locally advanced HPV16 + HNSCC as low-dose and self fractionating nature of radiation delivered by the mAbs could help to avoid severe side effects of EBRT such as radiation mucositis.

\section{ACKNOWLEDGEMENTS}

ED is a Sylvia and Robert S. Olnick Faculty Scholar in Cancer Research. The research was partially supported by NIH-designated Cancer Centre and Centre for AIDS Research, Albert Einstein College of Medicine (ED) and 5K12HD000849-FY24 Reproductive Scientist Development Program (RP).

\section{REFERENCES}

Ang KK, Harris J, Wheeler R, Weber R, Rosenthal DI, Nguyen-Tân PF, Westra WH, Chung CH, Jordan RC, Lu C, Kim H, Axelrod R, Silverman CC, Redmond KP, Gillison ML (2010) Human papillomavirus and survival of patients with oropharyngeal cancer. $N$ Engl J Med 363: 24-35.

Bañuelos CA, Banáth JP, Kim JY, Aquino-Parsons C, Olive PL (2009) gammaH2AX expression in tumors exposed to cisplatin and fractionated irradiation. Clin Cancer Res 10: 3344-3353.

Chen FM, Taylor CR, Epstein AL (1989) Tumor necrosis treatment of ME-180 human cervical carcinoma model with 131I-labeled TNT-1 monoclonal antibody. Cancer Res 49: 4578-4585.

Colnot DR, Quak JJ, Roos JC, de Bree R, Wilhelm AJ, Snow GB, van Dongen GA (2001) Radioimmunotherapy in patients with head and neck squamous cell carcinoma: initial experience. Head Neck 3: 559-565.

Dadachova E, Wang XG, Casadevall A (2007) Targeting the virus with radioimmunotherapy in virus-associated cancer. Cancer Biother Radiopharm 22: 303-308.

Duarte VM, Han E, Veena MS, Salvado A, Suh JD, Liang LJ, Faull KF, Srivatsan ES, Wang MB (2010) Curcumin enhances the effect of cisplatin in suppression of head and neck squamous cell carcinoma via inhibition of IKK $\beta$ protein of the NFKB pathway. Mol Cancer Ther (2010) 10: $2665-2675$.

Harris M, Wang X-G, Jiang Z, Goldberg GL, Casadevall A, Dadachova E (2011) Radio-immunotherapy of experimental head and neck squamous cell carcinoma (HNSCC) with E6-specific antibody using a novel HPV-16 positive HNSCC cell line. Head Neck Oncol 3: 9.

Hoffmann M, Lohrey C, Hunziker A, Kahn T, Schwarz E (2004) Human papillomavirus type $16 \mathrm{E} 6$ and E7 genotypes in head-and-neck carcinomas. Oral Oncol 40: 520-524.

Huang YT, Ravi Kumar AS (2012) Potential for truncating the scan length of restaging FDG-PET/CT after chemoradiotherapy in head and neck squamous cell carcinoma. Nucl Med Commun 33(5): 503-508.

Kaur P, McDougall JK (1989a) HPV-18 immortalization of human keratinocytes. Virology 173: 302-310.

Kaur P, McDougall JK, Cone R (1989b) Immortalization of primary human epithelial cells coned cervical carcinoma DNA containing human papillomavirus type E6/E7 open reading frames. J Gen Virol 70: 1261-1266.
Kies MS, Holsinger FC, Lee JJ, William Jr. WN, Glisson BS, Lin HY, Lewin JS, Ginsberg LE, Gillaspy KA, Massarelli E et al. (2010) Induction chemotherapy and cetuximab for locally advanced squamous cell carcinoma of the head and neck: results from a phase II prospective trial. J Clin Oncol 28: 8-14.

Liu Z, Liu Y, Jia B, Zhao H, Jin X, Li F, Chen X, Wang F (2010) Epidermal growth factor receptor-targeted radioimmunotherapy of human head and neck cancer xenografts using 90Y-labeled fully human antibody panitumumab. Mol Cancer Ther 9: 2297-2308.

Niu G, Sun X, Cao Q, Courter D, Koong A, Le QT, Gambhir SS, Chen X (2010) Cetuximab-based immunotherapy and radioimmunotherapy of head and neck squamous cell carcinoma. Clin Cancer Res 16: 2095-2105.

Percoraro G, Morgan D, Defendi V (1989) Differential effects of human papillomavirus type 6,16 , and 18 DNAs on immortalization and transformation of human cervical epithelial cells. Proc. Natl Acad. Sci. USA 86: 563-567.

Phaeton R, Wang XG, Einstein MH, Goldberg GL, Casadevall A, Dadachova E (2010b) The influence of proteasome inhibitor MG132, external radiation, and unlabeled antibody on the tumor uptake and biodistribution of (188)Re-labeled anti-E6 C1P5 antibody in cervical cancer in mice. Cancer 116(S4): 1067-1074.

Phaeton R, Harris M, Jiang Z, Wang X-G, Einstein MH, Goldberg GL, Casadevall A, Dadachova E (2010a) Radioimmunotherapy with antibody to HPV-16 E6 oncoprotein is effective in experimental cervical tumor expressing low levels of E6. Cancer Biol Ther 10: 1041-1047.

Revskaya E, Jongco AM, Sellers RS, Howell RC, Koba W, Guimaraes AJ, Nosanchuk JD, Casadevall A, Dadachova E (2009) Radioimmunotherapy of experimental human metastatic melanoma with melanin-binding antibodies and in combination with dacarbazine. Clin Cancer Res 15: 2373-2379.

Rosenberg B (1985) Fundamental studies with cisplatin. Cancer 55: 2303-2306.

Schwarz JK, Lewis Jr JS, Pfeifer J, Huettner P, Grigsby P (2012) Prognostic significance of p16 expression in advanced cervical cancer treated with definitive radiotherapy. Int J Radiat Oncol Biol Phys 84(1): 153-157.

Sehouli J, Runnebaum IB, Fotopoulou C, Blohmer U, Belau A, Leber H, Hanker LC, Hartmann W, Richter R, Keyver-Paik MD, Oberhoff C, Heinrich G, Dubois A, Olbrich C, Simon E, Friese K, Kimmig R, Boehmer D, Lichtenegger W, Kuemmel SA (2012) Randomized phase III adjuvant study in high-risk cervical cancer: simultaneous radiochemotherapy with cisplatin (S-RC) versus systemic paclitaxel and carboplatin followed by percutaneous radiation (PC-R): a NOGGO-AGO Intergroup Study. Ann Oncol 23: 2259-2264.

Sharkey RM, Blumenthal RD, Behr TM, Wong GY, Haywood L, Forman D, Griffiths GL, Goldenberg DM (1997) Selection of radioimmunoconjugates for the therapy of well-established or micrometastatic colon carcinoma. Int J Cancer 72: 477-485.

Sharkey RM, Goldenberg DM (2006) Targeted therapy of cancer: new prospects for antibodies and immunoconjugates. CA Cancer J Clin 56: 226-243.

Trimble CL, Frazer IH (2009) Development of therapeutic HPV vaccines. Lancet Oncol 10: 975-980.

Wang XG, Revskaya E, Bryan RA, Strickler HD, Burk RD, Casadevall A, Dadachova E (2007) Treating cancer as an infectious disease-viral antigens as novel targets for treatment and potential prevention of tumours of viral etiology. PLoS ONE 2: el14.

This work is published under the standard license to publish agreement. After 12 months the work will become freely available and the license terms will switch to a Creative Commons AttributionNonCommercial-Share Alike 3.0 Unported License. 